\title{
PRINCIPAIS DEFEITOS EM QUEIJO MINAS ARTESANAL: UMA REVISÃO
}

\author{
Major defects in artisanal Minas cheese: a review
}

\author{
Denise Sobral ${ }^{1}$, Renata Golin Bueno Costa ${ }^{I}$, Junio César Jacinto de Paula ${ }^{1}$, \\ Vanessa Aglaê Martins Teodoro², Gisela de Magalhães Machado Moreiral, \\ Maximiliano Soares Pinto ${ }^{3}$
}

\begin{abstract}
RESUMO
A preferência do consumidor por queijos artesanais de leite cru vem crescendo continuamente devido à sua intensidade e variação de sabor se comparado ao queijo de leite pasteurizado. O desenvolvimento do sabor e aroma no queijo de leite cru é regido principalmente pela variada microbiota endógena existente e enzimas naturais do leite. O clima, a altitude, a pastagem nativa e outras características regionais permitem que o queijo Minas artesanal tenha um sabor típico e único. No entanto, a maioria dos queijos artesanais são fabricados de maneira rudimentar, seguindo tecnologias utilizadas pelos seus antepassados e este fato pode propiciar o aparecimento de defeitos, que acarretam perdas econômicas aos produtores. Grande parte dos defeitos pode ter origem na qualidade do leite destinado à fabricação, assim como na qualidade e quantidade dos ingredientes utilizados, técnicas de fabricação e maturação que podem aumentar o número de falhas. Nesta revisão, serão abordados os principais defeitos que surgem especificamente nos queijos artesanais, assim como suas origens, prevenção e reparação.
\end{abstract}

Palavras-chave: fermentação, contaminação, estufamento, qualidade.

\begin{abstract}
The consumer's preference for artisanal raw milk cheeses has been growing

1 Empresa de Pesquisa Agropecuária de Minas Gerais (EPAMIG), Instituto de Laticínios Cândido Tostes, Rua Tenente Luiz de Freitas, 116, bairro Santa Terezinha, 36045-560, Juiz de Fora, MG, Brasil. E-mail: denisesobral@epamig.br

2 Universidade Federal de Juiz de Fora (UFJF), Juiz de Fora, MG, Brasil.

3 Universidade Federal de Minas Gerais (UFMG), Montes Claros, MG, Brasil.

* Autor para correspondência.
\end{abstract}

Recebido / Received: 08/08/2017

Aprovado / Approved: 06/11/2017 
steadily, because of its taste intensity and variation compared to pasteurized cheese. The development of flavor and aroma in raw milk cheese is governed mainly by diversified endogenous microbiota and naturals milk enzymes. The weather, altitude, native pasture and others regional characteristics allow the artisanal Minas cheese to have a typical and unique flavor. However, most of artisanal cheeses are manufactured in a rudimentary way, following technologies used by their ancestor, and this fact can cause defects in cheeses, thus resulting in economic losses for producers. Many defects may be originated from the quality of milk for manufacture, as well as quality and quantity of the ingredients used, manufacturing and ripening procedures. In this review will be presented the major defects that arise specifically in artisanal cheeses, as well as their origins, prevention and repair.

Keywords: fermentation; contamination; blowing; quality.

\section{INTRODUÇÃO}

O queijo Minas artesanal é um dos mais antigos e tradicionais do Brasil. O estado de Minas Gerais é o maior produtor de queijos artesanais do país, reconhecidos pela sua importância cultural, histórica, social e econômica (SOBRAL, 2012). Nos últimos anos, nota-se maior preocupação em melhorar a qualidade dos queijos artesanais mineiros, devido ao aumento do número de treinamentos de produtores, as melhorias na estrutura física das queijarias, a regulamentação da produção e também a elevação no número de pesquisas e financiamentos por parte dos órgãos de fomento, com o intuito de aprimorar os conhecimentos sobre este assunto e possibilitar a fabricação de queijos mais seguros e de qualidade superior.

$\mathrm{Na}$ fabricação dos queijos artesanais a prevenção e correção dos defeitos são mais difíceis se comparadas aos queijos de leite pasteurizado. Isso ocorre, pois nos queijos artesanais a matéria-prima principal, ou seja, o leite, não pode ser padronizada como acontece na indústria. O leite não apresenta padrão físico-químico constante e pode variar ainda mais com as diferentes estações do ano. Também não são permitidas outras etapas que padronizam o produto, como a pasteurização, o acréscimo de fermento industrial, o aumento da temperatura de coagulação, dentre outros. Portanto, cabe ao artesão ou queijeiro responsável pela produção adequar a técnica de fabricação aos diferentes tipos de leite recebidos ao longo do ano e às temperaturas e condições ambientais da fabricação e maturação para obter queijos em perfeito estado.

Muitos produtores já fazem tais modificações empiricamente, com o respaldo de suas experiências na prática do dia a dia, como por exemplo, o aumento da dose de pingo no inverno. Nos meses mais frios, a temperatura do leite no momento da coagulação é mais baixa, devido à troca de calor com o ambiente. Sendo assim, muitos produtores aumentam a dose de pingo no inverno, para que ocorra aumento na acidez titulável, permitindo melhores condições de coagulação e dessoragem da massa, compensando a temperatura mais baixa. O aumento da dose de pingo também aumenta o número de bactérias endógenas, contribuindo, assim, com a fermentação que também poderia ser prejudicada pelo abaixamento de temperatura.

Todavia, ainda existem obstáculos na produção destes queijos que geram produtos de baixa qualidade e com elevado número de defeitos, acarretando perdas econômicas para o produtor. Sendo assim, neste trabalho foram catalogados os principais defeitos que 
aparecem nos queijos Minas artesanais, suas possíveis causas, prevenção e correção.

\section{REFERENCIAL TEÓRICO}

\section{Problemas relacionados à qualidade do leite}

\section{Leite de vacas com mastite}

A mastite é um processo inflamatório da glândula mamária causada pelos mais variados agentes. Os mais comuns são as bactérias dos gêneros estreptococos e estafilococos, além das bactérias do grupo coliformes (EMBRAPA ...., 2017).

A contagem de células somáticas (CCS) do leite pode indicar condições de sanidade do rebanho assim como o sistema de higiene pelo qual o leite foi obtido e manuseado. Quando a CCS é elevada pode ser indicativo da presença de patógenos causadores da mastite no úbere, responsáveis pela redução da produção de leite e da diminuição do rendimento no processamento de queijos (CASTRO et al., 2014).

O aumento da CCS tem sido associado a alterações nas características físico-químicas do leite que podem indiretamente interferir na fabricação de queijos. Sendo assim, nota-se em casos de vacas com mastite diminuição da concentração de alguns componentes do leite como caseína, gordura, cálcio, fósforo, lactose e aumento dos ácidos graxos livres de cadeia curta e das atividades proteolítica e lipolítica (COELHO et al., 2014).

A mastite também pode aumentar a concentração da lactoferrina, da lactoperoxidase e da plasmina, enzimas antimicrobianas que podem inibir a multiplicação dos microrganismos da cultura láctea e, assim, interferir nas condições da formação da coalhada (COELHO et al., 2014).

No queijo, as consequências do leite com altas CCS são: aumento no tempo de coagulação (devido à mudança do $\mathrm{pH}$ ); a coalhada fica menos firme; diminuição da atividade das bactérias láticas; no corte ocorrem maiores perdas de caseína e gordura no soro (queda no rendimento); diminuição de sinerese dos grãos e obtenção de queijos mais úmidos (COELHO et al., 2014).

Todas estas mudanças podem diminuir o rendimento de fabricação e também podem alterar o sabor dos queijos artesanais, devido à inibição das bactérias láticas presentes no leite e no pingo e, consequentemente, mudanças no complexo enzimático que atua na maturação do queijo (McSWEENEY, 2007).

É preciso trabalhar continuamente na prevenção e no controle de mastite, pois constitui uma enfermidade que pode surgir repentinamente, por se tratar de uma doença de manejo. Para se fazer uma prevenção adequada, é preciso considerar todo o controle zootécnico da propriedade. O diagnóstico da mastite clínica é realizado pela observação de alterações no leite, pelo teste da caneca de fundo escuro e pelos sinais da inflamação como a presença de dor, edema no úbere e modificação das características da secreção do leite. Para o diagnóstico da forma subclínica da mastite, dois testes são de grande importância: o California Mastitis Test (CMT) e a CCS (EMBRAPA ...., 2017). Quando os índices desta doença se elevam, significa que uma ou mais ações dentro do manejo estão sendo executadas de forma inadequada (EMBRAPA ...., 2017).

\section{Resíduos de antibióticos}

A principal fonte de resíduos de antibióticos em leite é originada do manejo inadequado de drogas no controle da mastite ou de outra doença infecciosa. A causa mais frequente é o uso indiscriminado de drogas veterinárias, sem controle de um médico veterinário e sem respeitar o período de carência (ARAÚJO et al., 2015). 
O principal problema causado pelos resíduos de antibióticos no leite para a fabricação de queijos artesanais é a inibição das bactérias láticas presentes no leite cru e no pingo, alterando todo o processo fermentativo. A inibição das bactérias láticas causa uma série de defeitos no queijo como: a massa do queijo não enxuga, não dá ponto, pois não há produção de acidez dentro do grão; a massa não adquire porosidade e retém mais soro; o queijo não dessora bem; o queijo não atinge pH desejado; aumenta o risco de formação de gás por coliforme que resistem mais ao antibiótico do que as bactérias láticas e encontram alto teor de lactose não fermentada. Outra característica importante é que o queijo pode ficar úmido e sem sabor, não maturando adequadamente.

Para controlar este tipo de defeito, deve-se realizar o monitoramento do uso de produtos veterinários, sem uso indiscriminado e respeitando os períodos de carência e condições de uso de acordo com cada fabricante e tipo de antibiótico. Algumas medidas devem ser adotadas para evitar resíduos de antibióticos no leite como: a implantação de programa de controle de mastite baseado em medidas preventivas, buscando reduzir a ocorrência de mastite no rebanho e desta forma, reduzir o uso de tratamentos; identificar todos os animais em tratamento e ordenhá-los separadamente e descartar o leite; respeitar estritamente o período de carência dos medicamentos; evitar o uso de antibióticos em doses ou esquemas de tratamento não recomendados pelo médico veterinário e instruir funcionários e ordenhadores sobre o correto uso de antibióticos nos animais em lactação (SANTOS, 2000).

\section{Problemas relacionados à fermentação}

\section{Estufamento precoce}

O estufamento precoce é processo fer- mentativo indesejável das bactérias do grupo coliforme ou de leveduras que fermentam a lactose com produção de gás. Neste processo, são formadas pequenas e numerosas olhaduras indesejáveis nos queijos, comprometendo sua aparência e o seu sabor (Figura 1) (McSWEENEY, 2007).

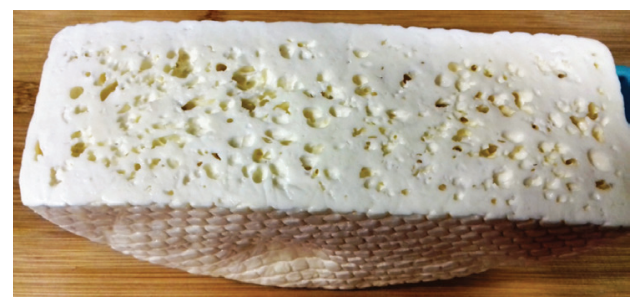

Figura 1 - Queijo artesanal apresentando o defeito de estufamento precoce

Algumas bactérias do grupo coliformes são indicadoras de contaminação fecal e, se as contagens são altas, podem indicar a presença potencial de agentes patogênicos. Este defeito é chamado estufamento precoce, pois aparece nas primeiras horas da fabricação do queijo, muitas vezes ainda no tanque de fabricação ou na salga (McSWEENEY, 2007).

Os principais compostos produzidos por bactérias do grupo coliforme são: ácido lático, ácido acético, etanol, $\mathrm{CO}_{2}, \mathrm{H}_{2}$. A produção de gás começa a se tornar visível quando a contagem de microrganismos atinge valores de aproximadamente 100 a 400 coliformes/g de queijo (McSWEENEY, 2007). Nos queijos artesanais, como não existe a etapa de pasteurização do leite, este defeito pode ocorrer com mais frequência.

Em um estudo realizado por Perin e colaboradores (2017), foi constatado em algumas amostras de queijo coletados nas regiões do Serro, Canastra, Serra do Salitre, Araxá e Campo das Vertentes um alto número do grupo coliformes que podem estar associados a problemas de higiene. Sobral et al. (2017) também encontraram contagens de colifor- 
mes totais e termolerantes acima do permitido pela legislação (MINAS GERAIS, 2008) em amostras de queijos Minas artesanais comercializados no mercado central de Belo Horizonte, MG. Estes estudos comprovam que há necessidade de uma medida corretiva para este defeito nas queijarias.

A produção de queijo Minas artesanal em verões chuvosos, ou seja, quando, há maior solubilização de matéria orgânica, somada às temperaturas mais elevadas, favorece a proliferação de microrganismos no ambiente, principalmente no solo. Neste período há maior dificuldade para o produtor em praticar corretamente os procedimentos de higiene e os riscos de contaminação são maiores. Tais efeitos explicam parte das variações nas contagens de coliformes nos queijos em diferentes épocas do ano (FIGUEIREDO et al., 2015).

A contaminação do leite e do queijo por estes microrganismos pode ter origem na falta de higiene do ordenhador ou da pessoa responsável por fabricar o queijo (visto que os queijos artesanais são muito manipulados), nas más condições de limpeza e sanitização das instalações e equipamentos, e na utilização de água contaminada, ou seja, condições precárias de higiene praticadas nas diferentes fases de obtenção do leite, fabricação e comercialização do queijo (McSWEENEY, 2007).
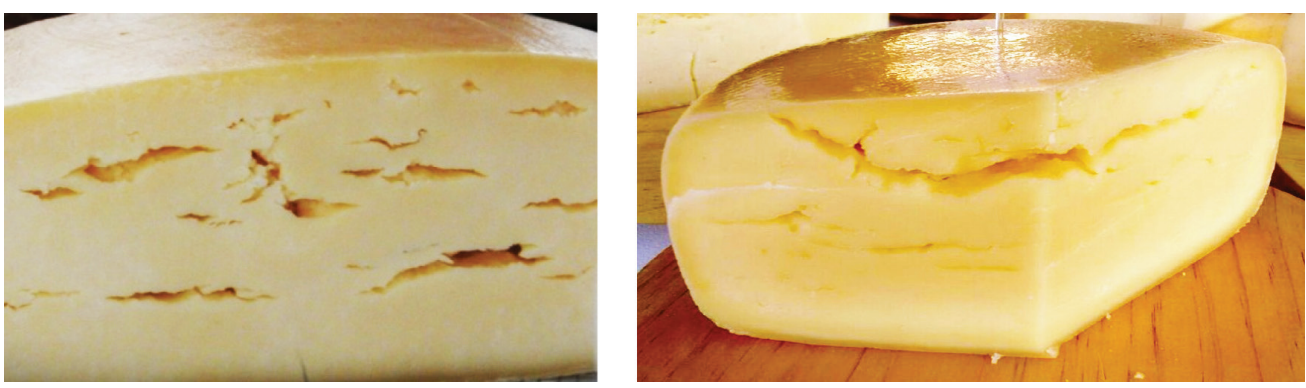

Figura 2 - Queijos Minas artesanais apresentando trincas internas típicas de estufamento tardio 
casca mais firme são mais susceptíveis ao surgimento de estufamento tardio. Queijo embalados a vácuo e com embalagens plásticas impermeáveis e queijos com $\mathrm{pH}$ mais elevado também possuem maior probabilidade de apresentarem este defeito (BRÄNDLE et al., 2016).

Um dos procedimentos adotados para reduzir a contagem bacteriana e o número de esporos de clostrídios no queijo é não utilizar o leite das vacas alimentadas com silagem para a fabricação de queijos (BRÄNDLE et al., 2016).

\section{Problemas relacionados ao sabor}

\section{Queijos salgados}

O excesso de sal, além de não ser uma prática saudável, pode interferir na maturação do queijo, pois inibe a microbiota desejável que faz com que os queijos artesanais tenham o sabor característico.

Em estudos realizados em queijos artesanais de Minas Gerais (FERRAZ et al., 2016; SOBRAL, 2012; TEODORO, 2012), é comum a variação do teor de sal em queijos da mesma procedência. Isso ocorre devido à falta de padronização da quantidade de sal utilizada no queijo. Sabe-se que a salga dos queijos artesanais é feita, na maior parte das vezes, sem uma medida exata da quantidade de sal empregada, que pode gerar queijos mais salgados que outros, mesmo se tratando de um mesmo lote.

A salga dos queijos artesanais é feita a seco, ou seja, aplica-se sal grosso ou refinado na casca dos queijos por um período de 6 a 8 horas. Cumprido esse tempo, faz-se a viragem do queijo, aplica-se sal na outra face e o queijo fica salgando por mais um período. Após a salga, os queijos são lavados para retirar o excesso. Nos casos em que o queijo é consumido ainda fresco, sem que tenha havido tempo suficiente para a difusão do sal, é possível ter percepções de gosto diferentes: salgado na superfície e sem sal no miolo. O queijo maturado, por sua vez, sofre desidratação quando o processo de cura é feito sem embalagem. Nesses casos, é comum haver uma concentração do teor de sal (SOBRAL, 2012).

O excesso de sal também é utilizado para mascarar sabores indesejáveis como o "sabor de curral" e melhorar o gosto de queijos amargos, ácidos ou rançosos (BEMFEITO et al., 2016), problemas que podem surgir em função da baixa qualidade do leite.

No inverno, devido ao maior teor de gordura do leite, o dessoramento dos queijos ocorre mais lentamente, o que também exige maior tempo de cura. Para compensar esse atraso na maturação e no dessoramento e continuar produzindo no ritmo exigido pelo mercado, alguns produtores usam uma quantidade maior de sal, o que pode gerar queijos mais salgados e mais amargos.

\section{Gosto amargo}

O gosto amargo é um problema que aparece em alguns tipos de queijos e vem sendo encontrado com frequência nos queijos artesanais. Na maior parte dos casos, este defeito é resultado do acúmulo de peptídeos hidrofóbicos e amargos, formados durante a fabricação e maturação dos queijos, devido a uma proteólise primária e secundária desequilibrada (FALLICO et al., 2005). Tais peptídeos são derivados particularmente da hidrólise ocorrida a partir da região $\mathrm{C}$-terminal hidrofóbica da $\beta$-caseína durante a proteólise (McSWEENEY, 2007; PAULA et al., 2017). Este desequilíbrio pode surgir devido a motivos diversos e, por isso, é um dos mais complexos defeitos de se resolver e de identificar o agente causador (O GOSTO..., 1992).

Normalmente os peptídeos amargos produzidos são naturalmente degradados a compostos não amargos por peptidases microbianas e contrabalançam a sua produção, 
evitando um excessivo acúmulo no queijo e aparecimento do gosto amargo. No entanto, quando há uma proteólise desordenada, este equilíbrio de formação/degradação é quebrado e o defeito pode acontecer (FALLICO et al., 2005). Quando a concentração de peptídeos amargos alcança ou excede o limite mínimo detectável pelo ser humano (também conhecido como threshold) devido à superprodução ou a degradação inadequada destes compostos, o indesejável gosto amargo é percebido no queijo pelos consumidores (FALLICO et al., 2005).

Em geral, os peptídeos amargos formados na proteólise primária são degradados por enzimas presentes no queijo, durante a proteólise secundária e o gosto tente a desaparecer. No entanto, quando na proteólise primária ocorre excesso da atividade das enzimas do coagulante (retidas na massa durante a fabricação do queijo) ou quando a atividade das peptidases é insuficiente para se degradar peptídeos amargos formados, o defeito pode surgir (McSWEENEY, 2007).

A escolha do tipo de coalho/coagulante e dose utilizada são importantes para evitar este defeito. Os coagulantes vegetais e de origem fúngica podem causar o amargor. Coalhos com maior proporção de pepsina, muito utilizados na produção dos queijos artesanais, também tendem a aumentar este defeito, devido à formação de peptídeos amargos pela ação inespecífica da pepsina. Doses de coalho acima das recomendadas pelo fabricante também podem provocar o amargor, devido ao maior acúmulo desta enzima na massa de queijo. O ideal é utilizar a dose de coalho/coagulante recomendada pelo fabricante. Além disso, o leite com acidez mais elevada, retém mais coagulante na massa, o que pode aumentar a chance de aparecer este defeito (PAULA et al., 2017).

$\mathrm{Na}$ fabricação dos queijos Minas artesanais, é comum a utilização de coalho com alto teor de pepsina, que é uma enzima mais proteolítica e menos específica que a quimosina, o que pode causar o gosto amargo e tornar este defeito mais comum em queijos maturados. Em um estudo realizado por Bemfeito e colaboradores (2016), foi observada grande variação no tempo de coagulação do leite durante a fabricação de dos queijos Minas artesanais da região da Canastra. Os autores concluíram que não havia padronização da quantidade de coalho usada pelos produtores, comprovando que o excesso de coalho pode ser também uma causa do aparecimento do gosto amargo.

Queijos com teores de sal e de umidade extremos (ou muito elevados ou muito baixos) tendem a apresentar o defeito. A solução está em equilibrar estes teores nos queijos artesanais, desde que o queijo ainda mantenha suas características. O excesso de sal e queijos muito secos tendem a apresentar uma menor proteólise secundária devido à redução da atividade enzimática da microbiota lática, lática, podendo contribuir para o acúmulo de peptídeos amargos nos queijos (FALLICO et al., 2005).

Por outro lado, queijos pouco salgados e com alto teor de umidade tendem a ocasionar uma superprodução destes peptídeos, sendo a atividade das peptidases incapazes de degradá-los, causando seu acúmulo na massa e gerando o defeito de gosto amargo (O GOSTO..., 1992). Em queijos com alto teor de umidade e baixo teor de gordura o defeito pode ser mais evidente, devido à redução do número de peptídeos hidrofóbicos na fase gordurosa do queijo. Já em queijos com baixo teor de sal ocorre o enfraquecimento das interações hidrofóbicas entre as caseínas o que facilita a ação do coagulante nestas regiões, particularmente na região C-terminal, resultando na produção excessiva de peptídeos hidrofóbicos (PAULA et al., 2017).

\section{Sabor de ranço}

A lipólise é um evento bioquímico que ocorre durante a maturação e pode contribuir 
gerando sabores desejáveis ou indesejáveis nos queijos. Quando a lipólise proporciona sabores indesejáveis, é popularmente chamada de rancidez. A degradação da gordura durante a fabricação de queijos, que causa defeitos de sabor, pode ocorrer por meio da rancidez hidrolítica ou rancidez oxidativa (COLLINS et al., 2003).

O ranço oxidativo ocorre devido à oxidação dos ácidos graxos insaturados com formação de peróxidos, óxidos, aldeídos e cetonas. As reações de oxidação podem ser influenciadas por diversos fatores, sendo os principais o calor e a luz (COLLINS et al., 2003). Os ácidos graxos poliinsaturados dos queijos são especialmente propensos à oxidação, o que leva à formação de vários aldeídos insaturados que são fortemente aromatizados e podem resultar no sabor de ranço. No entanto, a oxidação lipídica não ocorre de forma significativa em queijos, provavelmente devido ao seu baixo potencial redox $(250 \mathrm{mV})$ e a presença de antioxidantes naturais (por exemplo, vitamina $\mathrm{E}$ ), não sendo um evento de grande preocupação (COLLINS et al., 2003).

O ranço hidrolítico ocorre de forma mais frequente na formação de sabores indesejáveis no queijo. Este defeito acontece devido à ação das lipases (provenientes do leite ou de microrganismos) na gordura do queijo, com liberação de ácidos graxos livres de cadeia curta (butírico, caproico, caprílico, cáprico). Estes ácidos graxos livres (AGL) formados durante a lipólise são importantes precursores de reações catabólicas, produzem compostos voláteis e contribuem para o sabor (COLLINS et al., 2003). Ácidos graxos livres (AGL) de cadeia longa ( $>12$ átomos de carbono) desempenham um papel menor no sabor do queijo devido ao seu elevado limiar de percepção. Já os AGL de cadeia curta e intermediária (C4: 0-C12: 0) têm maior percepção e cada um dá uma nota de sabor característica.O ácido butanóico, por exemplo, contribui com o sabor de ranço, o ácido hexanóico possui sabor pungente, característico de queijo maturado por mofos azuis e o ácido octanóico pode gerarsabor de cera, sabão, ranço e frutado. O limite de concentração e percepção dos AGL podem contribuir positivamente ou negativamente para o aroma do queijo (COLLINS et al., 2003).

Em um estudo do perfil sensorial dos queijos Minas artesanais produzidos na região da Canastra (BEMFEITO et al., 2016), o sabor de ranço foi percebido em algumas das amostras, mas não foi dominante. Os autores deste estudo acreditam que o sabor de ranço muitas vezes é mascarado pelo excesso de sal do queijo, o que torna este defeito menos perceptível.

Para evitar defeitos de racidez em queijos, recomenda-se trabalhar com leite de boa qualidade microbiológica, obtido por uma higiene adequada durante a ordenha (GIGANTE, 2004). Outro fator que causa problemas de rancidez no leite e no queijo é o excesso de bombeamento ou turbulência no leite. Nos queijos artesanais, apesar da não utilização de bombeamento mecânico do leite, pode ocorrer turbulência do leite entre o processo de ordenha e passagem deste leite para a bombona ou recipiente onde ocorrerá a coagulação e assim ocorrer rompimento dos glóbulos. O glóbulo de gordura fica mais suscepítvel ao ataque das lipases quando é rompido e, assim, aumenta as chances de ocorrer o saborde ranço no queijo, por isso deve ser evitado.

\section{Problemas de contaminação}

\section{Ácaros}

Os ácaros mais comuns que infectam a superfície dos queijos são as espécies Acarus siro, Acarus farris, Acarus immobilis, Tyrophagus putrescentiae, Tyrophagus longior, Tyrophagus neiswanderi, Tyrophagus palmarum, e Tyrolichus casei. Os queijos 
infectados por ácaros apresentam orifícios ou túneis formados na casca e também possuem uma característica peculiar e visível a olho nu que é presença de uma poeira fina na superfície dos queijos (Figura 5), devido ao acúmulo de dejetos e ácaros mortos no queijo (CARVALHO et al, 2017).

Para alguns, a presença de ácaros pode ser considerada um defeito, no entanto, hoje em dia alguns consumidores apreciam queijos contaminados por ácaros e acreditam que a presença dos ácaros influenciam positivamente o sabor e o aroma dos queijos. Com a ascensão do queijo artesanal no Brasil e a introdução de diferentes técnicas de maturação, produtores brasileiros iniciaram, também, a realização da maturação de queijos na presença de ácaros, com o objetivo de conferir um sabor característico como os queijos fabricados em outros países (CARVALHO et al, 2017).

Em um estudo realizado com queijo parmesão no Brasil (CARVALHO et al, 2017) foram encontrados ácaros identificados como Tyrophagus putrescentiae. Segundo este estudo, esta espécie está presente em diversas regiões do mundo, podendo ser encontrada na poeira doméstica ou em grãos armazenados, assim como em outros alimentos estocados. No entanto, ainda não existem estudos suficientes de identificação de ácaros nos queijos
Minas artesanais e pesquisas devem ser realizadas com este propósito.

Apesar das vantagens de se maturar queijos com ácaros, a sua presença nos queijos pode causar reações alérgicas e problemas gastrointestinais em algumas pessoas. A presença dos ácaros é mais comum em queijos secos, duros e de longa maturação. $\mathrm{O}$ ambiente mais favorável para o crescimento de ácaros é um ambiente seco, com baixa umidade relativa do ar na camara de maturação (FURTADO, 2017).

Depois de infectada por ácaros, a desinfecção da câmara de maturação é dificil de ser resolvida, portanto, aconselha-se prevenir para que este tipo de contaminação não apareça. Para isso, deve-se manter a temperatura e umidade relativa do ar (URA) da câmara adequados, realizar a inspeção regular dos queijos e das prateleiras de maturação, no sentido de verificar a presença dos ácaros, virar regularmente os queijos, não deixar pedaços de queijos nas câmaras por longos períodos e fazer limpeza regular destas câmaras e prateleiras (FURTADO, 2017).

\section{Fungos filamentosos}

Os mofos por si só não são agentes patogênicos veiculados por alimentos, no entanto, seus metabólicos secundários conhecidos

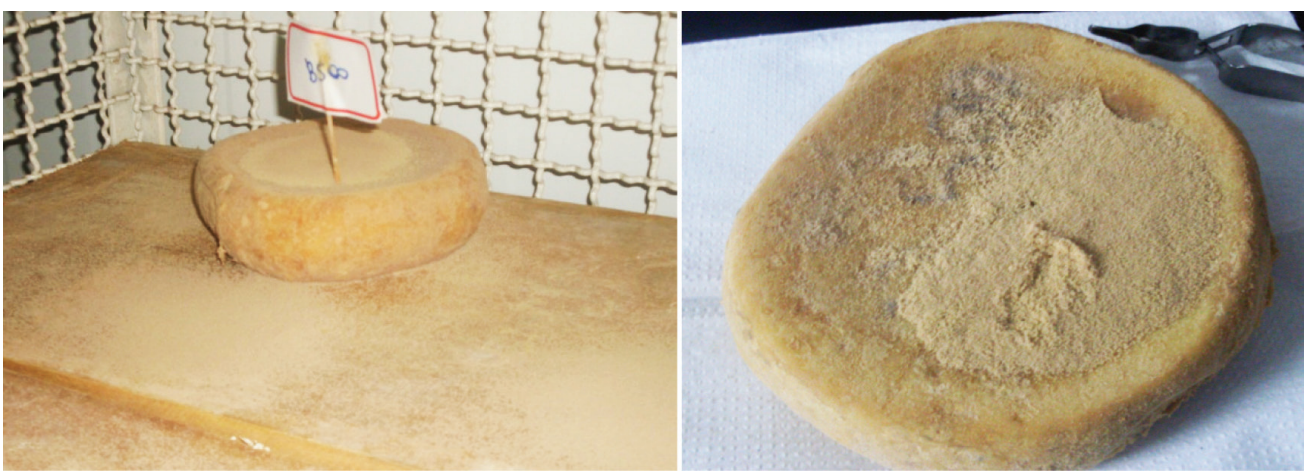

Figura 5 - Presença de ácaros na superfície do queijo e na câmara de maturação 
como micotoxinas possuem efeitos toxicológicos agudos ou crônicos (BECKERALGERI et al., 2016; BENKERROUM, 2016; ZACARCHENCO et al., 2011).

As micotoxinas são substâncias tóxicas que preocupam a saúde pública devido aos efeitos graves que podem causar nos seres humanos tais como carcinogenicidade, genotoxicidade/teratogenicidade, mutagenicidade, nefrotoxicidade, hepatotoxicidade, imunotoxicidade, além de outros fatores debilitantes (BENKERROUM, 2016). Uma vez que a micotoxina é produzida no alimento, a sua descontaminação é um processo difícil ou impossível de ser alcançado, devido a sua resistência aos tratamentos utilizados para sua inativação (BECKER-ALGERI et al., 2016; BENKERROUM, 2016).

Em um estudo realizado por BECKERALGERI e colaboradores (2016) foi demonstrado que há registros de ocorrência de micotoxinas em queijos do Brasil e outros países como Grécia, Líbia, Paquistão, dentre outros.

$\mathrm{Na}$ fabricação de algumas variedades de queijos, tanto industriais quanto artesanais, o crescimento de fungos filamentosos pode fazer parte da microbiota desejável como é o caso dos mofos brancos (Penicillium camemberti) em queijos como o Camembert e o Brie e os fungos azuis (Penicillium roqueforti) em queijos como o Gorgonzola e o Roquefort (ZACARCHENCO et al., 2011). Em alguns casos o crescimento de fungos filamentosos pode ser indesejável e indicativo de contaminação.

Os esporos de fungos filamentosos do ambiente necessitam de oxigênio para crescimento e esporulação, crescem na casca de queijos expostos ao ar e não se espera seu desenvolvimento em queijos embalados a vácuo (ZACARCHENCO et al., 2011). No entanto, em algumas situações, os fungos podem crescer em bolsas de ar existentes entre a embalagem e a superfície do queijo, porém o crescimento é limitado pela quantidade de oxigênio residual. Os níveis de oxigênio podem determinar as espécies de fungos encontradas. Os fungos mais comuns encontrados em queijos embalados a vácuo são Penicillium spp. (especialmente $P$. commune, um fungo azul) e Cladosporium spp. (especialmente C. cladosporioides, um fungo preto). Outros bolores encontrados em diferentes queijos são Aspergillus, Fusarium, Mucor, Scopulariopsis e Verticillium (ZACARCHENCO et al., 2011).

A pasteurização do leite $\left(72{ }^{\circ} \mathrm{C}\right.$ por 15 segundos) é suficiente para inativar fungos e seus esporos do leite cru, no entanto, algumas espécies produzem ascósporos resistentes ao tratamento térmico e conseguem sobreviver a tratamentos de $90{ }^{\circ} \mathrm{C}$ por 5 minutos, como é o caso do fungo Byssochlamys fulva. Estirpes desta espécie podem ser encontradas no leite e pode, possivelmente, produzir micotoxinas no queijo fabricado incluindo a byssotoxina $\mathrm{A}$, ácido bissoclâmico, patulina, verruculogênio, fischerina e eupenifeldina (BENKERROUM, 2016).

A presença de fungos filamentosos é aceitável ou mesmo necessária em queijos especiais fabricados a partir de leite cru e com Denominação Origem Protegida (PDO) em todo o mundo e podem ser necessárias para os queijos artesanais brasileiros, depois de estudos que comprovem que não oferecem risco a saúde pública. Nestes queijos, os fungos estão envolvidos na maturação e podem ter origem na microbiota do leite cru, ambiente de maturação, como é o caso do queijo Roquefort, ou pode ser adicionado ao leite como culturas adjuntas quando o queijo é fabricado utilizando leite pasteurizado. Estes fungos desempenham um papel fundamental no desenvolvimento do sabor e da textura destas variedades de queijo (BENKERROUM, 2016).

Em um estudo realizado na região do Serro (CARDOSO et al., 2015), quatorze espécies de fungos foram obtidas a partir de 
queijo produzido durante a estação seca, e quinze espécies foram obtidas a partir de queijo produzido durante a estação chuvosa. As espécies predominantes no queijo Minas artesanal do Serro foram Debaryomyces hansenii, Kodamaea ohmerie, Kluyveromyces marxianus que atuam mudando as características sensoriais do queijo, por meio de enzimas lipolíticas e proteolíticas. Já na região da Canastra, foram encontrados 39 isolados de fungos filamentosos e leveduras capazes de fermentar a lactose, dentre eles Kluyveromyces lactis, Torulaspora delbruekii e Candida intermedia (ANDRADE et al., 2017).

Estirpes de fungos selvagens, cujo crescimento é propositadamente incentivado durante a fabricação de queijo com leite cru, como um meio para manter a sua autenticidade ou satisfazer as exigências dos queijos de DOP, são mais propensas a conter elevadas concentrações de micotoxinas. Isso ocorre devido à diversidade e identidades desconhecidas de espécies/estirpes de mofos envolvidas no processo de maturação e algumas destas podem ser altamente toxigênicas (BENKERROUM, 2016).

As medidas preventivas para o crescimento de mofos ainda são o método mais eficaz para prevenir micotoxinas. A aplicação de boas práticas de fabricação (BPF) e de ordenha é primordial para minimizar a contaminação de produtos lácteos por fungos filamentosos (BENKERROUM, 2016). Uma melhor compreensão do impacto de parâmetros como $\mathrm{pH}$, atividade de água, teor de sal e temperatura ideais para produção e estabilidade de micotoxinas pode reduzir a sua ocorrência em produtos lácteos. Embora controverso, condições ótimas de fermentação e de fabricação do queijo podem permitir a produção de níveis significativos de micotoxinas, como pode-se comprovar pela elevada incidência de micotoxinas de $P$. roqueforti em queijos azuis (BENKERROUM, 2016). Mudanças nas condições de fabricação dos queijos devem ser estudadas para que haja controle da contaminação, sem prejuízos às características do produto final.

Além das BPF, a pasteurização do leite destinado à fabricação de queijos é necessária para minimizar ainda mais a contaminação por mofos, no entanto, esta não é uma opção para a produção de queijos artesanais. As estirpes de mofos selecionadas para serem inoculadas no leite pasteurizado como culturas adjuntas e agentes da maturação não devem ser toxigênicas ou ter baixa toxicidade e são selecionadas para este fim (BENKERROUM, 2016).

$\mathrm{O}$ uso de fungicidas ou aditivos fungiostáticos (como a natamicina) quando permitidos pela legislação, devem ser utilizados. Outras medidas de combate compreendem embalagem a vácuo, a salga, a toalete e o armazenamento em baixas temperaturas, no entanto, não podem ser aplicados em todo tipo de queijo e devem ser estudados caso a caso (BENKERROUM, 2016, ZACARCHENCO et al., 2011).

\section{CONSIDERAÇÕES FINAIS}

Apesar do queijo Minas artesanal ser um produto tradicional de Minas Gerais e também ser destaque no cenário gastronômico nos dias atuais, ainda são necessárias muitas pesquisas nesta área, principalmente envolvendo a inocuidade do produto. Os produtores também devem ser treinados, com o intuito de melhorar a qualidade do queijo e reduzir o número de defeitos.

\section{AGRADECIMENTOS}

À FAPEMIG, pelo financiamento da pesquisa e concessão das bolsas BIPDT e BIC.

\section{REFERÊNCIAS}

ANDRADE, R. P. Yeasts from Canastra 
cheese production process: Isolation and evaluation of their potential for cheese whey fermentation. Food Research International, v. 91, p. 72-79, 2017.

ARAÚJO, G. B. Detecção de resíduo de antibiótico em leite in natura em laticínio sob inspeção federal. Scientia Plena, v. 11, n. 4, p. 1-6, 2015.

BECKER-ALGERI et al. Mycotoxins in Bovine Milk and Dairy Products: A Review. Journal of Food Science, v. 81, n. 3, p. 544$552,2016$.

BENKERROUM, N. Mycotoxins in dairy products: A review. International Dairy Journal, v. 62, p. 63-75, 2016.

BEMFEITO, R. M. et al. Temporal dominance of sensations sensory profile and driversof likingof artisanal Minas cheese produced in the region of Serra da Canastra, Brazil. Journal of Dairy Science, v. 99, n. 10, p. 1-12, 2016.

BRÄNDLE, J. et al. Relevance and analysis of butyric acid producing clostridia in milk and cheese. Food Control, v. 67, p. 96-113, 2016.

CARDOSO et al. The influence of seasons and ripening time on yeast communities of a traditional Brazilian cheese. Food Research International, v. 69, p. 331-340, 2015.

CASTRO, K. A. de et al. Efeito da contagem de células somáticas sobre a qualidade dos queijos prato e mussarela. Revista Brasileira de Tecnologia Agroindustrial, v. 8, n. 1, 2014.

CARVALHO, de M. M. et al. Identificação e determinação de procedimentos de coleta de amostras de ácaros em queijos. In: CONGRESSO NACIONAL DE LATICÍNIOS,
31, 2017, Juiz de Fora, Anais eletrônicos... Disponível em: <http://www.epamig.br/ publicacoes/cnl/>. Acesso em: 17 ago. 2017.

COELHO, K. O. et al. Efeito da contagem de células somáticas sobre o rendimento e a composição físico-química do queijo muçarela. Arquivo Brasileiro de Medicina Veterinária e Zootecnia, v. 66, n. 4, p. 1237 1250, 2014.

COLLINS, Y. F. et al. Lipolysis and free fatty acid catabolism in cheese: a review of current knowledge. International Dairy Journal, v. 13, p. 841-866, 2003.

EMBRAPA GADO DE LEITE. Controle de mastite. Disponível em: <http://www. cnpgl.embrapa.br/sistemaproducao/410216controle-de-mastite>. Acesso em: 08 ago. 2017.

FALLICO, V. Evaluation of Bitterness in Ragusano Cheese. Journal of Dairy Science, v. 88 , n. 4 , p. $1288-1300,2005$.

FERRAZ, W. M. et al. Queijo Minas artesanal da serra da Canastra: Influência do ambiente na maturação. In: XXV CONGRESSO BRASILEIRO DE CIÊNCIA E TECNOLOGIA DE ALIMENTOS, 2016, Gramado. Anais... Gramado: SBCTA, 2016.

FIGUEIREDO, S. P. et al. Características do leite cru e do queijo minas artesanal do Serro em diferentes meses. Archives of Veterinary Science, v. 19, n. 2, p. 68-81, 2015.

FURTADO, M. M. Principais problemas dos queijos. São Paulo: Setembro Editora, 2017. $256 \mathrm{p}$.

GIGANTE, M. L. Importância da qualidade do leite no processamento de produtos lácteos. In: DURR, J. W., CARVALHO, M. 
P., SANTOS, M. V. O Compromisso com a Qualidade do Leite. Passo Fundo: Editora UPF, 2004, v. 1, p. 235-254.

McSWEENEY, P. L. H. Cheese Problems Solved, USA: CRC Press, 2007, 425p.

MINAS GERAIS. Decreto 44.864 de 01 de agosto de 2008. Altera o regulamento da lei $\mathrm{n}^{\circ} 14.185$, de 31 de janeiro de 2002, que dispõe sobre o processo de produção de Queijo Minas Artesanal. Minas Gerais Diário do Executivo, pag. 1, col. 2, 02 de agosto de 2008 .

O GOSTO amargo em queijos. Ha-La Biotec, Valinhos, n. 9, mai., 1992.

PAULA, J. C. J. de et al. Gosto amargo em queijo Minas Frescal: possíveis causas e prevenção. Revista Indústria de Laticínios, n. 127, p. $118-122,2017$.

PERIN, L. M. et al. Bacterial ecology of artisanal Minas cheeses assessed by culture dependent and - independent methods. Food Microbiology, v. 65, p. 160-169, 2017.

SANTOS, M. V. Como evitar a presença de resíduos de antibióticos no leite? Milk Point. Disponível em: <https://www.milkpoint. com.br/radar-tecnico/qualidade-do-leite/ como-evitar-a-presenca-de-residuos-deantibioticos-no-leite-16166n.aspx>. Acesso em: 08 ago. 2017.

SOBRAL, D. Efeito da nisina na contagem de Staphylococcus aureus e nas características do queijo Minas artesanal da região de Araxá. 2012. 116 p. Tese (Doutorado em Ciência e Tecnologia de Alimentos) - Universidade Federal de Viçosa, Viçosa, 2012.

SOBRAL, D. et al. Qualidade microbiológica de queijo Minas artesanal da Canastra em estabelecimentos comerciais. In: $\mathrm{CON}$ GRESSO NACIONAL DE LATICÍNIOS, 31, 2017, Juiz de Fora, Anais eletrônicos... Disponível em: <http://www.epamig.br/publicacoes/cnl/>. Acesso em: 17 ago. 2017.

TEODORO, V. A. M. Efeito do uso de nisina no desenvolvimento de Staphylococcus aureus e nas propriedades do queijo Minas artesanal da serra da Canastra - MG. 2012. 133 p. Tese (Doutorado em Ciência e Tecnologia de Alimentos) - Universidade Federal de Viçosa, Viçosa, 2012.

ZACARCHENCO, P. B. et al. Bolores e leveduras em queijos. Revista Leite e Derivados, n. 129, set/out, p. 92-99, 2011. 